\title{
DIAGNÓSTICO ESPAÇO-TEMPORAL DA OCORRÊNCIA DE HERBICIDAS NAS ÁGUAS SUPERFICIAIS E SEDIMENTOS DO RIO CORUMBATAÍ E PRINCIPAIS AFLUENTES
}

Eduardo Dutra de Armas*, Regina Teresa Rosim Monteiro, Paula Munhoz Antunes, Maria Alice Penna Firme dos Santos e Plinio Barbosa de Camargo

Centro de Energia Nuclear na Agricultura, Universidade de São Paulo, CP 96, 13400-970 Piracicaba - SP, Brasil

Rosangela Blotta Abakerli

Embrapa Meio Ambiente, CP 69, 13820-000 Jaguariúna - SP, Brasil

Recebido em 9/6/06; aceito em 30/1/07; publicado na web em 6/8/07

\begin{abstract}
SPATIAL-TEMPORAL DIAGNOSTIC OF HERBICIDE OCCURRENCE IN SURFACE WATERS AND SEDIMENTS OF CORUMBATAÍ RIVER AND MAIN AFFLUENTS. Residues of herbicides from sugarcane were monitored in waters and sediments of Corumbataí River and tributaries. Ametryne, atrazine, simazine, hexazinone, glyphosate, and clomazone were detected in water samples, with negligible levels of ametryne and glyphosate in sediment samples. The area of recharge of the Guarani aquifer presented the highest triazine and clomazone levels. The triazines were detected at higher levels, with atrazine above Brazil's potability and quality standards. Total herbicide levels at some sampling points were 13 times higher than the European Community potability limit. There is no Brazilian standard for ametryne, although the risk is larger due to ametryne's higher toxicity for the aquatic biota.
\end{abstract}

Keywords: monitoring; pesticide; water quality.

\section{INTRODUÇÃO}

Os agrotóxicos representam os produtos mais amplamente encontrados em corpos hídricos superficiais e subterrâneos do mundo todo, em função do amplo uso em áreas agrícolas e urbanas. Eles compreendem uma variedade de moléculas com distintas propriedades que lhes conferem diferentes graus de persistência ambiental, mobilidade e potenciais tóxico, carcinogênico, mutagênico e teratogênico ou algum efeito endócrino a diversos organismos não-alvos, inclusive o ser humano. Os extensos e dispendiosos programas de monitoramento dos EUA têm demonstrado resultados alarmantes, constatando a presença de mais de 70 diferentes agrotóxicos em águas subterrâneas de 38 estados, estando acima dos limites aceitáveis em 17 deles ${ }^{1}$.

O Brasil é um dos três maiores consumidores mundiais destes produtos, movimentando 3,1 bilhões de dólares em $2003^{2}$, que associado à diversidade edafo-climática do país, resulta em grande preocupação quanto ao comportamento ambiental destas moléculas e possível contaminação de corpos hídricos. O comprometimento da qualidade das águas superficiais ocasionado por estes e outros produtos e também por atividades degradadoras da paisagem levou à adoção de medidas que permitissem a reversão do quadro atual e prevenção de danos futuros. Isto culminou primeiramente na criação dos Comitês de Bacias Hidrográficas, $\mathrm{CBH}$, como unidade básica do Sistema Integrado de Gerenciamento de Recursos Hídricos, SIGRH, do Estado de São Paulo, por determinação da Lei Estadual 7.663/91 ${ }^{3}$, tendo por base que as atividades desenvolvidas dentro de uma unidade de área, cujos limites são definidos pela divisão de águas, são as principais condicionantes da quantidade e qualidade da água. Posteriormente, o Governo Federal instituiu a Política Nacional de Recursos Hídricos e criou o Sistema Nacional de Gerenciamento de Recursos Hídricos por meio da Lei $9.433 / 97^{4}$.

*e-mail: eduarmasrs@yahoo.com.br
Desde então, a presença de agrotóxicos em águas brasileiras passou a ser evidenciada por diversos estudos, sendo os organoclorados as moléculas freqüentemente monitoradas ${ }^{5-7}$. Os estudos envolvendo estas moléculas, de uso proibido no Brasil, estão associados à verificação de vestígios de sua presença devido à elevada persistência ambiental e ao comércio e uso ilegais, resultando na exigência de seu monitoramento pela legislação brasileira. Um número restrito de programas de monitoramento ou simples caracterização de ocorrência, constando de um pequeno número de outras moléculas de diferentes classes de agrotóxicos e grupos químicos já foi conduzido em distintas bacias hidrográficas brasileiras $^{8-13}$, evidenciando problemas até então pouco estudados e com estratégias de mitigação não implantadas.

No Estado de São Paulo, maior consumidor brasileiro de agrotóxicos, responsável por $18,64 \%$ do valor comercializado em $2003^{2}$, estudos baseados principalmente em processos matemáticos de estimação apontam para o risco de contaminação de águas subterrâneas $^{14,15}$, além de alguns estudos que evidenciaram a presença de algumas moléculas em corpos hídricos superficiais e subterrâneos.

Dentro do Estado de São Paulo, a bacia hidrográfica do Rio Piracicaba é uma das que apresenta maior grau de comprometimento de qualidade de água, sendo a pioneira no estabelecimento de medidas para contornar esta situação. A presença de compostos organoclorados como BHC, aldrim e endossulfam já foi evidenciada em sedimentos desta bacia, bem como $\gamma$-BHC, heptacloro e DDT no bivalve Anodontites trapesialis ${ }^{16}$. Resíduos de PCP, HCB e quatro congêneres de PCBs também foram determinados em água e principalmente em sedimentos, com níveis de $\mathrm{HCB}$ excedendo o padrão de potabilidade da Organização Mundial de Saúde, OMS, de $10 \mathrm{ng} \mathrm{L}^{-1}$ nos municípios de Santa Bárbara d'Oeste, Sumaré e Campinas ${ }^{17}$. No entanto, há um completo desconhecimento sobre a presença de outras moléculas nos corpos hídricos desta bacia.

A sub-bacia do Rio Corumbataí, integrante da bacia do Rio Piracicaba, compreende uma região amplamente explorada por atividades agropastoris e a cana-de-açúcar é a cultura de maior ex- 
pressão. Seu cultivo tem grande representatividade no mercado nacional de agrotóxicos, principalmente com herbicidas, movimentando 251 milhões de dólares, o que equivale a $8 \%$ das vendas em $2003^{2}$. Produtos empregados nesta cultura têm grande potencial para a contaminação de águas superficiais e subterrâneas, devido a sua mobilidade, como é o caso do tebutiurom, que foi encontrado até mesmo nas águas profundas do aqüífero Guarani, na região de Ribeirão Preto-SP9 .

A sub-bacia do Rio Corumbataí, representada principalmente pelo rio de mesmo nome, é de grande importância para o abastecimento público, para fins domiciliares e industriais. Porém, avaliações espaço-temporais da qualidade de suas águas ${ }^{18,19}$ apontam uma mudança de qualidade em alguns trechos, variando entre as Classes 1 e 4, segundo os padrões estabelecidos na Resolução CONAMA $357 / 05^{20}$. Estudos ecotoxicológicos apontam para alterações de qualidade manifestadas por vários indicadores biológicos, inclusive em pontos próximos às nascentes deste rio $^{21}$, onde há presença de pequenas áreas de proteção ambiental, com vegetação ciliar arbórea e de difícil acesso, com ausência de atividade industrial, mas com a presença de atividade agrícola diversificada, em solo arenoso. Diagnóstico efetuado para esta bacia ${ }^{22}$ aponta para problemas de redução de vazão nos rios e poluição de origem pontual, gerada por atividades industriais e despejo de esgotos, não existindo qualquer consideração sobre as fontes difusas em função da ausência de informações, quantificando esta forma de poluição.

A ampla ocupação desta bacia com o cultivo de cana-de-açúcar é preocupante, uma vez que muitos dos produtos empregados apresentam níveis toxicológicos elevados, com grande tendência de atingirem os corpos hídricos. Seu monitoramento não é exigido legalmente, através da Portaria 518/04 do Ministério da Saúde, $\mathrm{MS}^{23}$. A lista de produtos é pequena, baseada em órgãos internacionais, sem considerar as características ambientais dos diferentes estados brasileiros, onde as diferenças edafo-climáticas irão determinar exposições diferenciadas para os produtos empregados nas culturas locais. Além disso, a determinação do monitoramento de agrotóxicos pela presente portaria não exige uma definição de épocas mais adequadas para coleta e análise de resíduos, que sejam condizentes com as épocas de uso dos mesmos, limitando-se a uma análise semestral.

Tais aspectos são extremamente relevantes, conforme apontado por Armas et al..$^{24}$, que determinaram o uso principalmente de herbicidas na sub-bacia do Rio Corumbataí, com tendências sazonais de consumo, que devidamente caracterizadas permitem uma melhor definição de épocas e de produtos a serem incluídos no programa de monitoramento. Muitos produtos são empregados em período chuvoso, condicionando a uma maior probabilidade de carreamento para os corpos hídricos. No entanto, o uso de moléculas em períodos de seca não determina a ausência de risco de poluição, uma vez que, de acordo com as características dos solos e com as propriedades dos agrotóxicos, um transporte subsuperficial, via fluxo de base, poderá ocorrer, exigindo uma caracterização temporal da ocorrência de moléculas nos corpos hídricos.

Alguns órgãos ambientais mundiais definiram esquemas de avaliação de periculosidade, baseados em valores únicos de parâmetros como meia-vida, toxicidade a alguns organismos e propriedades físico-químicas. Segundo Dulka ${ }^{25}$, isto seria apropriado somente para definir se um perigo existe potencialmente, mas não serviria para ser utilizado em decisões regulamentares por autoridades governamentais. Porém, serviria para indicar a necessidade de aprofundamento nos estudos para definição da segurança ambiental, visto que o risco é função do nível de exposição que poderia ocorrer em vários compartimentos do ambiente e da toxicidade inerente de cada produto àqueles organismos associados com estes compartimentos. Em 2005, os testes ecotoxicológicos foram integrados à legislação federal sobre qualidade das águas superficiais destinadas ao abastecimento humano e à vida aquática. A Resolução CONAMA $357 / 05^{20}$ prevê as possíveis interações entre substâncias e a presença de contaminantes passíveis de causar danos aos seres vivos.

A falta de investimentos em programas de monitoramento é um fator limitante para a real definição do grau de contaminação das águas superficiais e subterrâneas brasileiras, contrapondo com os Estados Unidos, que investem anualmente volumes de cerca de US\$ 240 milhões em programas de monitoramento e controle de poluição ${ }^{26}$. O monitoramento de agrotóxicos em bacias hidrográficas torna-se ainda mais importante se considerarmos a baixa correlação de estudos de lixiviação feitos em laboratório com os resultados obtidos em condições de campo.

O presente trabalho teve por objetivo o diagnóstico espaçotemporal da ocorrência de moléculas herbicidas de diferentes grupos químicos nas águas e sedimentos do Rio Corumbataí e seus afluentes. Este trabalho faz parte de um projeto de Políticas Públicas financiado pela Fundação de Amparo à Pesquisa do Estado de São Paulo, FAPESP (Processo no 01/02954-4), servindo de subsídio aos processos de avaliação da qualidade da água desta bacia e definição de metas para o Plano de Bacias elaborado pelo Comitê das Bacias dos Rios Piracicaba, Capivari e Jundiaí.

\section{PARTE EXPERIMENTAL}

\section{Área de estudo}

A sub-bacia do Rio Corumbataí (Figura 1) abrange uma área de $1.710 \mathrm{~km}^{2}$, sendo integrante da bacia do Rio Piracicaba, que compreende a $1^{\text {a }}$ zona hidrográfica da rede hídrica do Estado de São Paulo, Brasi1 ${ }^{27}$. O principal manancial é o Rio Corumbataí, com $170 \mathrm{~km}$ de extensão, nascendo no município de Analândia e desembocando no Rio Piracicaba, no município de mesmo nome. Entre os seus afluentes, destacam-se o Rio Passa Cinco, drenando uma extensa área de cultivo de cana-de-açúcar explorada por minifúndios e latifúndios, e o Ribeirão Claro, o qual drena a área urbana do município de Santa Gertrudes e parte do município de Rio Claro, bem como uma área de cultivo de cana-de-açúcar. $\mathrm{O}$ cultivo de cana-de-açúcar é a principal atividade agrícola da bacia, totalizando $43.663,16$ ha, o que representava $25,57 \%$ da área da bacia em $1999^{28}$. A área apresenta altitudes variando de $1040 \mathrm{~m}$ na sua nascente, no município de Analândia, a 460 m, próximo à foz no Rio Piracicaba. Declividades inferiores a $2 \%$ representam $40 \%$ da área da bacia e as superiores a $45 \%$ estão restritas a $1,33 \%$ da superfície, situadas nas regiões norte e noroeste ${ }^{28}$, resultando em uma das sub-bacias do Rio Piracicaba com maior intensidade de áreas com risco de erosão ${ }^{22}$.

A análise de resíduos de herbicidas empregados no cultivo de cana-de-açúcar foi efetuada em 8 pontos de amostragem (Figura 1), georreferenciados através de uma unidade receptora de GPS ("Global Position System"), ajustada para o Sistema de Coordenadas Geográficas Datum WGS84. Destes pontos, 6 estão localizados na calha principal do Rio Corumbataí e um em cada um dos dois principais afluentes deste rio, denominados Ribeirão Claro e Passa Cinco, permitindo avaliar a contribuição destes afluentes para o aporte de agrotóxicos no Rio Corumbataí (Tabela 1).

\section{Coleta e tratamento de amostras}

Amostras de água foram coletadas por um período de 1 ano, nos dias 9 de março, 23 de agosto e 18 de novembro de 2004 e 14 de fevereiro de 2005, com auxílio de balde de aço inoxidável, ar- 


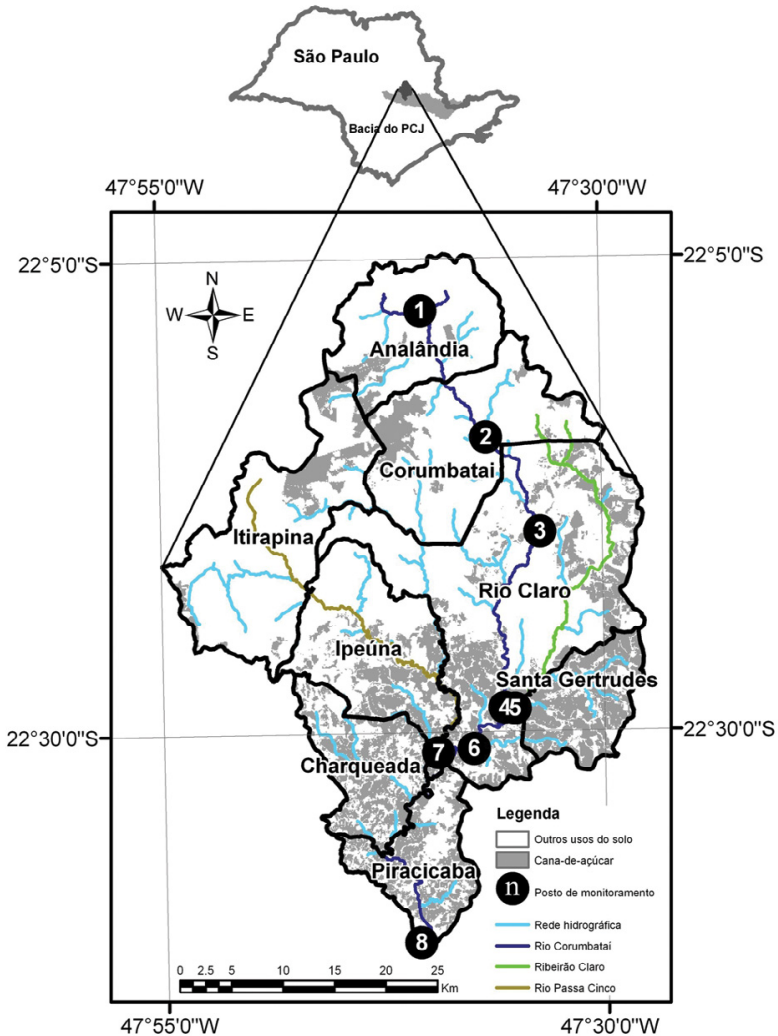

Figura 1. Localização da sub-bacia do Rio Corumbataí, áreas de cultivo de cana-de-açúcar e localização dos pontos de amostragem

mazenadas em frascos de polietileno (3 L), devidamente identificadas e mantidas em caixas de isopor, com gelo, para o transporte até o laboratório, onde foram mantidas congeladas a $-20{ }^{\circ} \mathrm{C}$ até o início da análise de resíduos. A descontaminação do equipamento de coleta foi efetuada antes de cada amostragem com álcool etílico p.a., seguida de enxágüe exaustivo com água destilada. Os frascos para armazenamento das amostras foram previa- mente lavados, mantidos em solução detergente sem fósforo $2 \%$ (v/v) por $24 \mathrm{~h}$ e, posteriormente, em solução de ácido nítrico $10 \%$ (v/v) por $24 \mathrm{~h}$, enxaguados exaustivamente com água destilada e com acetona p.a. para secagem rápida, sendo mantidos fechados para evitar contaminação. A temperatura da água, oxigênio dissolvido, $\mathrm{pH}$ e condutividade elétrica foram medidas simultaneamente à coleta das amostras de água.

Amostras de sedimento foram coletadas, concomitante às amostras de água, em diversos pontos no meio e/ou nas margens do rio,

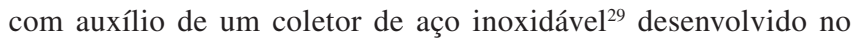
Laboratório de Ecotoxicologia do Centro de Energia Nuclear na Agricultura/USP, colocadas em sacos plásticos duplos devidamente identificados e mantidos em caixas de isopor, com gelo, para o transporte até o laboratório, onde foram preservadas a $-20^{\circ} \mathrm{C}$ até o início das análises.

\section{Análise de resíduos}

Os herbicidas monitorados e as datas de coleta foram definidos a partir do levantamento temporal de uso de agrotóxicos no cultivo de cana-de-açúcar na bacia do Rio Corumbataí, elaborado por Armas et al. ${ }^{24}$. Os herbicidas trifluralina, atrazina, simazina, clomazona, acetocloro, ametrina, isoxaflutol, pendimetalina, diurom, tebutiurom, hexazinona e sulfentrazona foram analisados por um método multi-resíduos e glifosato isoladamente, conforme procedimentos descritos abaixo.

\section{Análise de glifosato}

As amostras de água $(500 \mathrm{~mL})$, com $\mathrm{pH}$ ajustado a 4,0, foram submetidas à extração de glifosato em resina complexante Chelex®100 na forma férrica e os extratos obtidos, limpos em coluna de troca aniônica AG1-X8, concentrados a vácuo e analisados por cromatografia líquida de alta eficiência (HPLC). As amostras de sedimento $(20 \mathrm{~g})$ foram secas em estufa com circulação de ar a $25^{\circ} \mathrm{C}$, peneiradas em malha de $2 \mathrm{~mm}$ e o glifosato foi extraído com solução ácida aquosa, sendo os extratos limpos em resina de troca catiônica AG 50-W, concentrados a vácuo e analisados por HPLC ${ }^{30}$.

Tabela 1. Descrição dos pontos de amostragem

\begin{tabular}{|c|c|c|c|}
\hline Ponto de Amostragem & Código do ponto & Descrição & Localização geográfica e altitude \\
\hline 1 & Coru01 & $\begin{array}{l}\text { Rio Corumbataí, a montante do } \\
\text { município de Analândia }\end{array}$ & $\begin{array}{c}22^{\circ} 07^{\prime} 44,9^{\prime \prime} \mathrm{S} ; \\
47^{\circ} 40^{\prime} 4,8^{\prime \prime} \mathrm{O} ; 649 \mathrm{~m}\end{array}$ \\
\hline 2 & Coru02 & $\begin{array}{l}\text { Rio Corumbataí, a jusante do município de } \\
\text { Corumbataí, próximo a uma área de } \\
\text { extração de areia }\end{array}$ & $\begin{array}{c}22^{\circ} 14^{\prime} 30,3^{\prime \prime} \mathrm{S} ; \\
47^{\circ} 36^{\prime} 30,1^{\prime \prime} \mathrm{O} ; 574 \mathrm{~m}\end{array}$ \\
\hline 3 & Coru03 & $\begin{array}{l}\text { Rio Corumbataí, a montante do município de } \\
\text { Rio Claro, junto ao ponto de captação de } \\
\text { água do DAE }\end{array}$ & $\begin{array}{c}22^{\circ} 19^{\prime} 28,6^{\prime \prime} \mathrm{S} ; \\
47^{\circ} 33^{\prime} 30,4^{\prime \prime} \mathrm{O} ; 561 \mathrm{~m}\end{array}$ \\
\hline 4 & Coru04 & $\begin{array}{l}\text { Rio Corumbataí, a jusante do município de } \\
\text { Rio Claro, antes do aporte das águas do } \\
\text { Ribeirão Claro }\end{array}$ & $\begin{array}{c}22^{\circ} 28^{\prime} 45,4^{\prime \prime} \mathrm{S} ; \\
47^{\circ} 35^{\prime} 28,4^{\prime \prime} \mathrm{O} ; 541 \mathrm{~m}\end{array}$ \\
\hline 5 & RibCla & $\begin{array}{l}\text { Ribeirão Claro, próximo à foz no } \\
\text { Rio Corumbataí }\end{array}$ & $\begin{array}{c}22^{\circ} 28^{\prime} 47,6^{\prime \prime} \mathrm{S} \\
47^{\circ} 35^{\prime} 11,1^{\prime \prime} \mathrm{O} ; 539 \mathrm{~m}\end{array}$ \\
\hline 6 & Coru05 & $\begin{array}{l}\text { Rio Corumbataí, município de Rio Claro, } \\
\text { distrito de Assistência, após a confluência } \\
\text { com o Ribeirão Claro e antes do aporte do } \\
\text { Rio Passa Cinco }\end{array}$ & $\begin{array}{c}22^{\circ} 30^{\prime} 54,1^{\prime \prime} \mathrm{S} ; \\
47^{\circ} 37^{\prime} 26,4^{\prime \prime} \mathrm{O} ; 508 \mathrm{~m}\end{array}$ \\
\hline 7 & PasCin & $\begin{array}{l}\text { Rio Passa Cinco, próximo à foz no } \\
\text { Rio Corumbataí }\end{array}$ & $\begin{array}{c}22^{\circ} 31^{\prime} 5,6^{\prime \prime} \mathrm{S} \\
47^{\circ} 39^{\prime} 26,1^{\prime \prime} \mathrm{O} ; 497 \mathrm{~m}\end{array}$ \\
\hline 8 & Coru06 & $\begin{array}{l}\text { Rio Corumbataí, próximo à foz no } \\
\text { Rio Piracicaba }\end{array}$ & $\begin{array}{c}22^{\circ} 41^{\prime} 4,5^{\prime \prime} \mathrm{S} \\
47^{\circ} 40^{\prime} 37,2^{\prime \prime} \mathrm{O} ; 495 \mathrm{~m}\end{array}$ \\
\hline
\end{tabular}


A análise dos resíduos foi efetuada em cromatógrafo líquido Merck-Hitachi, com derivatização pós-coluna com o reagente OPAMERC e detecção por fluorescência. Foi utilizada uma coluna Aminex A-9, na forma potássica, de $300 \mathrm{~mm}$ de comprimento x 4,6 mm d.i. e uma pré-coluna de $150 \mathrm{~mm}$ de comprimento x 4,6 $\mathrm{mm}$ d.i. Para a reação de derivatização foram empregados dois tubos de aço em espiral, de 3,0 m de comprimento x 0,02" d.i. x 1/16" d.e. para condução da solução oxidante de hipoclorito de cálcio e da solução de o-ftalaldialdeído-mercaptoetanol (OPA-MERC). Foram adotadas as seguintes condições cromatográficas: temperatura das colunas: $50{ }^{\circ} \mathrm{C}$, temperatura da espiral de reação com oxidante: $38^{\circ} \mathrm{C}$, fluxo da fase móvel: $0,7 \mathrm{~mL} \mathrm{~min}^{-1}$, fluxo da solução oxidante: 0,2 mL min ${ }^{-1}$, fluxo da solução OPA-MERC: $0,2 \mathrm{~mL} \mathrm{~min}^{-1}$, volume injetado: $100 \mu \mathrm{L}$, detector: $E_{x} 350 \mathrm{~nm} ; E_{m} 440 \mathrm{~nm}$.

\section{Análise dos demais herbicidas}

As amostras de água $(500 \mathrm{~mL})$ foram submetidas à extração em fase sólida em discos de extração Bakerbond Speedisk ${ }^{\mathrm{TM}}$ contendo os sorventes sílica gel (10 $\mu$ irregular) modificada com octyl $\mathrm{C}_{8}$, de $60 \AA$, para extração por fase reversa de herbicidas aniônicos, apolares e moderadamente polares e divinilbenzeno (DVB $\mathrm{H}_{2} \mathrm{O}-$ phobic) (10 $\mu$ esférico), de $150 \AA$, para extração de herbicidas levemente polares a apolares, por meio de adsorção.

Os discos de $\mathrm{C}_{8}$ e DVB foram previamente condicionados com acetato de etila, metanol e água $\mathrm{pH}$ 2,0 e diclorometano, metanol e água $\mathrm{pH} 2,0$, respectivamente. Os discos foram sobrepostos na sequiência $\mathrm{C}_{8}$ sobre DVB, a amostra de água foi aplicada após ajuste do pH para <2,0 com $\mathrm{HCl} 1,0 \mathrm{M}$ e o disco foi seco mediante aplicação de vácuo por $5 \mathrm{~min}$. Os discos foram separados e procedeu-se à eluição dos analitos do disco de $\mathrm{C}_{8}$ com 2 alíquotas de $10 \mathrm{~mL}$ de acetato de etila PR e do disco de DVB com 2 alíquotas de $10 \mathrm{~mL}$ de diclorometano PR. Os eluatos foram recolhidos em tubos tipo Nessler e os solventes foram evaporados com fluxo de nitrogênio em banho de $35-38^{\circ} \mathrm{C}$, até um volume aproximado de $2 \mathrm{~mL}$. A troca de solvente foi realizada transferindo-se para outro frasco $1 \mathrm{~mL}$ de eluatos oriundos dos discos de $\mathrm{C}_{8}$ e DVB e ressuspendendo-os com $2 \mathrm{~mL}$ de fase móvel acetonitrila (40)/água (60) para análise por HPLC/UV-vis. Uma alíquota de $1 \mathrm{~mL}$ do eluato do disco de $\mathrm{C}_{8}$ foi transferida e redissolvida com $2 \mathrm{~mL}$ de tolueno para injeção em sistema CG/NPD ${ }^{31}$.

Uma alíquota de $20 \mathrm{~g}$ do sedimento foi agitada mecanicamente com $100 \mathrm{~mL}$ de metanol PR por $2 \mathrm{~h}$. O extrato foi filtrado e evaporado até o volume de $2 \mathrm{~mL}$, realizando-se troca de solvente com acetato de etila:cicloexano (1:1), seguido por ressuspensão do volume até $5 \mathrm{~mL}$ em tubo graduado. Um volume de $3 \mathrm{~mL}$ do extrato foi eluído em sistema de cromatografia de permeação em gel com uma mistura de acetato de etila:cicloexano (1:1) a um fluxo de $5 \mathrm{~mL} \mathrm{~min}{ }^{-1}$. A fração inicial de $100 \mathrm{~mL}$ foi descartada e recolhida a fração de $80 \mathrm{~mL}$, que foi evaporada até atingir $3 \mathrm{~mL}$. O extrato da amostra purificado foi analisado por CG/NPD, não sendo possível analisar os herbicidas por HPLC/UV-vis.

Os herbicidas trifluralina, atrazina, simazina, clomazona, acetocloro, ametrina, isoxaflutol e pendimetalina foram analisados em um cromatógrafo a gás HP-6890 equipado com detector termo-iônico específico a nitrogênio e fósforo (CG/NPD), utilizando-se uma coluna capilar DB-5 de $30 \mathrm{~m}$ de comprimento x 0,25 mm d.i. x 1,0 $\mu \mathrm{m}$ de espessura de fase estacionária e gás hélio a um fluxo constante de $2,0 \mathrm{~mL} \mathrm{~min}^{-1}$. Foi utilizado o modo splitless com o injetor mantido a $250{ }^{\circ} \mathrm{C}$, volume injetado de $1 \mu \mathrm{L}$, detector a $325^{\circ} \mathrm{C}$ e programação do forno de $90^{\circ} \mathrm{C}$ por $1 \mathrm{~min}$ com rampa de $10{ }^{\circ} \mathrm{C} \mathrm{min}-1$ até atingir $240{ }^{\circ} \mathrm{C}$, seguindo a $20^{\circ} \mathrm{C} \mathrm{min}$ mé $^{-1}$ ate0 ${ }^{\circ} \mathrm{C}$.

Os herbicidas diurom, tebutiurom, hexazinona e sulfentrazona foram analisados em cromatógrafo líquido Shimadzu, com detector
UV-vis operando a 254 e $230 \mathrm{~nm}$, a $80{ }^{\circ} \mathrm{C}$ (HPLC/UV-vis). Foi utilizada uma coluna de fase reversa $\mathrm{C}_{18}$ de $25 \mathrm{~cm}$ de comprimento $\mathrm{x} 4,6 \mathrm{~mm}$ d.i. $\mathrm{x} 5,0 \mu \mathrm{m}$ de tamanho de partícula, mantida a $38{ }^{\circ} \mathrm{C}$ e volume injetado de $100 \mu \mathrm{L}$. A fase móvel selecionada foi ácido acético $0,15 \%$ :acetonitrila $(60: 40)$ nos primeiros 5 min com gradiente até $20 \mathrm{~min}$ atingindo a proporção 20:80 (ácido acético $0,15 \%$ :acetonitrila) a um fluxo de $0,6 \mathrm{~mL} \mathrm{~min}^{-1}$.

\section{Recuperações e desempenho dos métodos}

A eficiência das metodologias utilizadas para a determinação dos herbicidas foi avaliada realizando-se experimentos de recuperação com uma amostra de água de torneira, fortificada com glifosato a $10 \mu \mathrm{g} \mathrm{L}^{-1}$ e demais herbicidas a $1 \mu \mathrm{g} \mathrm{\textrm {L } ^ { - 1 }}$ e com $20 \mathrm{~g}$ de sedimento, fortificado com glifosato e demais herbicidas a $0,5 \mathrm{e}$ $1,0 \mathrm{mg} \mathrm{kg}^{-1}$, respectivamente. Foi considerada como faixa de aceitabilidade para os resultados quantitativos valores de recuperação compreendidos entre 70 e $120 \%$.

Para determinação do limite de detecção (LOD) e limite de quantificação (LOQ) foram usadas soluções mistas de padrões dos herbicidas, no intervalo de concentrações de 0,01 a $0,1 \mu \mathrm{g} \mathrm{mL} \mathrm{m}^{-1}$ para o sistema CG/NPD e no intervalo de 0,002 a $0,08 \mu \mathrm{g} \mathrm{mL} \mathrm{m}^{-1}$ para HPLC/UV-vis. As soluções foram preparadas pela técnica de diluições sucessivas a partir de soluções estoque de $1000 \mathrm{mg} \mathrm{L}^{-1}$ dos herbicidas individuais em metanol ou água (HPLC/UV-vis) e tolueno (CG/NPD). O LOD e o LOQ foram estabelecidos com base nos parâmetros da curva analítica obtidos por regressão linear dos resultados de cinco injeções de cada concentração a partir das Equações 1 e 2 .

$$
\begin{aligned}
& L O D=3,3 \times \frac{\sigma}{S} \\
& L O Q=10 \times \frac{\sigma}{S}
\end{aligned}
$$

onde $\sigma$ é a estimativa do desvio padrão da resposta obtido pela regressão linear e S, a inclinação ou coeficiente angular da curva analítica.

\section{RESULTADOS E DISCUSSÃO}

A metodologia para análise de glifosato permitiu atingir LOD de $0,01 \mu \mathrm{g} \mathrm{mL}^{-1}$ e LOQ de $1,0 \mu \mathrm{g} \mathrm{L}^{-1}$ para $500 \mathrm{~mL}$ de água e de 0,05 $\mathrm{mg} \mathrm{kg}^{-1}$ para $20 \mathrm{~g}$ de sedimento. Para os herbicidas do grupo das triazinas e das dinitroanilinas, o LOD foi de $0,01 \mu \mathrm{g} \mathrm{mL}^{-1}$, sendo observados LODs maiores para isoxaflutol $\left(0,04 \mu \mathrm{g} \mathrm{mL}^{-1}\right)$ e

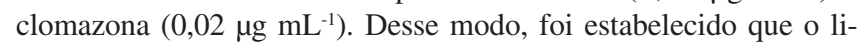
mite de quantificação para os herbicidas analisados por CG/NPD seria de $0,3 \mu \mathrm{g} \mathrm{L}^{-1}$ para $500 \mathrm{~mL}$ de água e de $0,01 \mathrm{mg} \mathrm{kg}^{-1}$ para $20 \mathrm{~g}$ de sedimento. Os limites de detecção para os herbicidas analisados no sistema HPLC/UV-vis variaram entre 0,003 e $0,02 \mu \mathrm{g} \mathrm{mL}{ }^{-1}$, sendo estabelecido um LOQ de $0,2 \mu \mathrm{g} \mathrm{L}^{-1}$ para $500 \mathrm{~mL}$ de água.

Observou-se baixa recuperação para ametrina analisada em amostras de água coletadas em fevereiro/2005, podendo ter sido eventualmente perdida durante a evaporação dos extratos devido a sua volatilidade. As demais moléculas apresentaram valores de recuperação dentro da faixa de aceitabilidade. Os cromatogramas típicos de água de torneira fortificada com padrões analíticos podem ser visualizados na Figura 2.

A presença de resíduos em amostras de água dá-se basicamente em uma fração dissolvida e/ou adsorvida aos colóides em suspensão, sendo a tendência de particionamento um aspecto determinado pelas propriedades físico-químicas das moléculas em estudo, bem como dos colóides e do solvente. A metodologia analíti- 

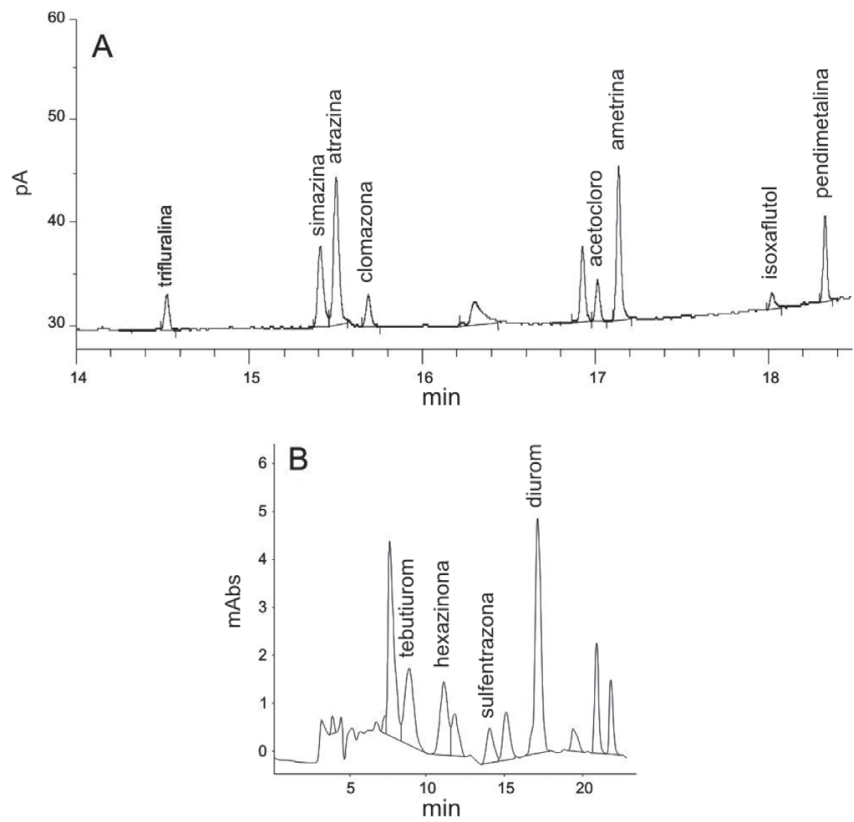

Figura 2. Cromatogramas de uma amostra de água de torneira fortificada com padrões analíticos em nível de 1,0 $\mu \mathrm{g} \mathrm{L}^{-1}$. A) extraída em disco de $C_{8}$ e analisada por CG/NPD; B) extraída em disco de $C_{8}$ e analisada por HPLC/UV-vis

ca empregada não permite a separação destas frações, sendo os resultados deste estudo referentes ao resíduo total em água.

É obviamente interessante conhecer a fração que contém maior parte da molécula, uma vez que a forma dissolvida apresenta maior biodisponibilidade, vindo a atingir organismos não-alvos e não sendo eficientemente removida pelos processos convencionais de tratamento de água. Porém, o baixo conteúdo de sólidos em suspensão nos pontos de amostragem torna este tipo de abordagem extremamente dispendiosa devido ao volume de amostra necessário para uma varredura completa de vários compostos, sendo relevante em estudos posteriores, caso haja constatação de valores totais muito elevados. Em uma tentativa de avaliação deste particionamento, foram coletados aproximadamente $200 \mathrm{~L}$ de água no período chuvoso e obtidos $12 \mathrm{~g}$ de sólidos por centrifugação, sendo estimada a necessidade de um volume superior a $1.000 \mathrm{~L}$ de água para obtenção da massa de sólidos necessária para o procedimento analítico.

Para muitas moléculas amplamente empregadas no cultivo de cana-de-açúcar na sub-bacia do Rio Corumbataí, não foram encontrados resíduos totais em amostras de água e sedimento. Foram detectados quali-quantitativamente resíduos de herbicidas dos grupos químicos das triazinas (ametrina, atrazina e simazina), das triazinonas (hexazinona), das isoxazolidinonas (clomazona) e da glicina substituída (glifosato) em amostras de água, no período de estudo. Apenas ametrina, em nível quantificável em um único local, e glifosato, abaixo do limite de quantificação, em várias épocas e locais, foram detectados em amostras de sedimento. Este comportamento está associado a sua composição, que é basicamente arenosa (ao redor de 98\%), com o conteúdo de carbono variando de 0,015 a $0,88 \%$ e apresentando frações argilosas e siltosas $(<63 \mu \mathrm{m})$ muito baixas $(2 \%)$, as quais tendem a manter-se em suspensão ${ }^{29}$. Todas estas moléculas são enquadradas em classes toxicológicas III (medianamente tóxico) e IV (pouco tóxico) ${ }^{32}$.

A ocorrência de número maior de moléculas (atrazina, ametrina, simazina, glifosato e clomazona) e em níveis mais elevados foi observada em amostras de água coletadas no mês de novembro, coincidindo com o período inicial de chuvas, mas não necessariamente com o período de maior aplicação.
Os meses de fevereiro e março, que compreendem parte do período de plantio de cana - planta-de-ano e meio, não apresentaram níveis quantitativos de resíduos de herbicidas em amostras de água, sendo observada apenas a presença de glifosato em níveis inferiores ao limite de quantificação. Não foram coletadas amostras nos pontos Coru04 e PasCin em fevereiro/2005 devido à impossibilidade de acesso, em decorrência de chuvas intensas antecedendo o momento de amostragem.

No mês de agosto, caracterizado como o período de seca, apenas o herbicida hexazinona foi detectado em níveis quantitativos, uma vez que este é o período recomendado para o uso de algumas formulações à base desta molécula, devido a problemas de toxicidade para a cana-de-açúcar quando aplicado em períodos chuvosos, principalmente em solos arenosos ${ }^{33}$. Glifosato não foi analisado neste período por indicação do levantamento de Armas et al.$^{24}$, que apontou tendência sazonal de consumo deste herbicida limitado ao período compreendido entre os meses de setembro e junho, com maior intensidade de dezembro a janeiro.

Apesar do predomínio de cana-de-açúcar na bacia em estudo, algumas destas moléculas detectadas, como glifosato e triazinas, são também empregadas na citricultura, que ocupa $2,8 \%$ da área da bacia, principalmente na região norte. Estudos já apontaram a contribuição não-agrícola, principalmente por estações de tratamento de esgoto, com muitos agrotóxicos para as águas superficiais, como atrazina $^{34,35}$, glifosato ${ }^{36}$, diurom e mecoprop ${ }^{34}$. Há também a necessidade de apontar a existência de indústrias de agrotóxicos situadas próximo ao Rio Corumbataí no município de Rio Claro.

As triazinas foram os herbicidas presentes em níveis mais elevados (ametrina $>$ atrazina $>$ simazina), o que era previsível em virtude de sua mobilidade, persistência, solubilidade em água e adsorção relativamente fraca ao solo, que favorecem o seu transporte via escoamento superficial, lixiviação e deposição atmosférica ${ }^{37}$, além do seu amplo uso, como já apontado pelos índices de particionamento descritos por Armas et al. ${ }^{24}$. Foram observados níveis quantificáveis de ametrina, atrazina e simazina variando entre 0,7-2,9 $\mu \mathrm{g} \mathrm{L}^{-1}, 0,6-2,7 \mu \mathrm{g} \mathrm{L} \mathrm{L}^{-1}$ e 0,3-0,6 $\mu \mathrm{g} \mathrm{L} \mathrm{L}^{-1}$, respectivamente.

Dentre estas triazinas, a ametrina é a que apresenta maior solubilidade em água e menor tendência de ser adsorvida ao solo, em oposição à simazina, que apresenta menor mobilidade. As triazinas ainda são, no mundo todo, os herbicidas mais presentes nas águas superficiais e subterrâneas, vindo a representar $80,7 \%$ dos contaminantes encontrados em mais de 100 mil amostras de água superficial e subterrânea analisadas na Alemanha Ocidental, sendo a atrazina a responsável por $59,7 \%$ dos $\operatorname{casos}^{38}$.

Um aspecto importante a ser aqui considerado é a ausência do herbicida acetocloro em qualquer amostra analisada, cuja proposta de substituinte para ametrina e atrazina torna-se uma alternativa viável, quando se consideram as perdas para corpos hídricos, devido à baixa tendência de mobilidade apontada tanto pelo índice de particionamento "Groundwater Ubiquity Score" - GUS quanto pelo "Leaching Index" - $\mathrm{LEACH}^{24}$.

A presença de clomazona é um pouco inesperada frente a sua baixa mobilidade e uso. No entanto, se for analisado o seu padrão espacial de ocorrência, pode-se observar que os níveis quantificáveis $\left(0,4 \mu \mathrm{g} \mathrm{L}^{-1}\right)$ foram detectados exclusivamente na região norte da bacia, onde apesar da menor exploração da área com cana-de-açúcar, vislumbram-se as áreas de ocorrência de Neossolos Quartzarênicos ${ }^{28}$ e os maiores problemas de erosão $0^{22}$, que podem contribuir com material particulado ao corpo d'água, os quais podem conter o herbicida. Sua presença foi também verificada em outros locais da bacia, porém em níveis inferiores ao limite de quantificação.

O herbicida glifosato, apesar de ocupar lugar de destaque no mercado de herbicidas, não foi detectado em níveis quantificáveis, 
ocorrendo sempre em concentrações inferiores ao LOQ de 1,0 $\mu \mathrm{g}$ $\mathrm{L}^{-1}$ e bem aquém do padrão de potabilidade de 500,0 $\mu \mathrm{g} \mathrm{L}^{-1}$. Porém, foi a molécula mais frequientemente detectada, o que torna o índice de LEACH mais confiável que o GUS, os quais apontaram tendências extremamente distintas para este herbicida ${ }^{24}$. Apesar da forte tendência desta molécula em ligar-se às partículas de solo e apresentar uma taxa de degradação elevada, sua enorme solubilidade, considerada apenas no cálculo do LEACH, o torna passível de atingir as fontes de água, embora em níveis reduzidos que podem estar associados a sua rápida hidrólise em meio aquoso.

Comportamento semelhante foi observado com hexazinona, que apesar de não ser apontada como uma das mais móveis pelo índice GUS, ficando no limite das classes potencialmente móvel e móvel, apresenta um índice LEACH muito elevado, que apontou a tendência do seu transporte, confirmada pela sua presença nas amostras de água, variando de 0,3 a $0,5 \mu \mathrm{g} \mathrm{L}^{-1}$.

Como se pode observar, a adequada caracterização temporal do uso de agrotóxicos é uma etapa imprescindível para definir as épocas de amostragem e moléculas a serem analisadas, de modo a atingir otimização econômica e técnica do monitoramento, uma vez que levantamentos preliminares não foram eficazes na determinação de resíduos de agrotóxicos nas águas da mesma área de estudo. Este aspecto deveria ser considerado pelas autarquias que detêm a concessão para captação, tratamento e distribuição de água, quando visam avaliar o padrão de potabilidade, atendendo à exigência de monitoramento semestral de agrotóxicos, segundo a Portaria 518/04 do MS.

De acordo com esta Portaria, que contém valores referência apenas para glifosato, atrazina e simazina, aqui detectados, somente atrazina foi encontrada em níveis superiores ao padrão $\left(2,0 \mu \mathrm{g} \mathrm{L}^{-1}\right)$ em dois pontos de amostragem no início do período de chuvas. Uma vez que o mesmo padrão é definido para a outra triazina (simazina), uma extrapolação para ametrina, sem qualquer critério toxicológico, faz com que sua presença em um ponto também esteja comprometendo a potabilidade. A legislação brasileira apenas define padrões individuais para agrotóxicos, determinados a partir da abordagem toxicológica para definição de diretrizes de qualidade de água potável da OMS. Desta forma, é permitida a ocorrência de 22 moléculas em uma mesma amostra de água desde que seus níveis individuais não sejam atingidos. Isto propiciaria a presença de uma carga de até $1 \mathrm{mg} \mathrm{L}^{-1}$ de agrotóxicos nas águas distribuídas à população, além de levar em conta um pequeno número de moléculas, frente à realidade brasileira.

Segundo o padrão de potabilidade adotado pela Comunidade Européia, valores mais restritivos que a referida Portaria são empregados, de modo a não ultrapassar $0,1 \mu \mathrm{g} \mathrm{\textrm {L } ^ { - 1 }}$ por agrotóxico e $0,5 \mu \mathrm{g} \mathrm{L}^{-1}$ para a soma de todos os agrotóxicos. Deste modo, com exceção do ponto Coru03, todos os demais apresentaram níveis totais de agrotóxicos de $2\left(1,0 \mu \mathrm{g} \mathrm{L}^{-1}\right)$ a $13\left(6,6 \mu \mathrm{g} \mathrm{L}^{-1}\right)$ vezes acima do padrão europeu de potabilidade. Porém, grandes críticas existem em torno destes limites, uma vez que nenhum critério toxicológico foi adotado no seu estabelecimento, sendo definidos próximo ao limite de detecção para garantir a ocorrência de água limpa na Europa, seguindo o princípio da precaução.

Não podemos generalizar que haverá ocorrência destes níveis anualmente nesta área e nem mesmo que estes sejam os níveis mais elevados a serem observados. O período de amostragem deste estudo coincidiu com anos atípicos em termos de pluviosidade, quando foram registrados valores abaixo da média nos meses de coleta de agosto de 2004 e fevereiro de 2005, precedidos de chuva intensa nos meses que os antecediam, que poderiam ter corroborado para estas ocorrências, devido à mobilização das moléculas em áreas de cultivo (Figura 3). Apesar da otimização do processo de coleta, o número de amostragens ainda é pequeno para que seja realizada qualquer inferência sobre o comportamento médio destas moléculas.

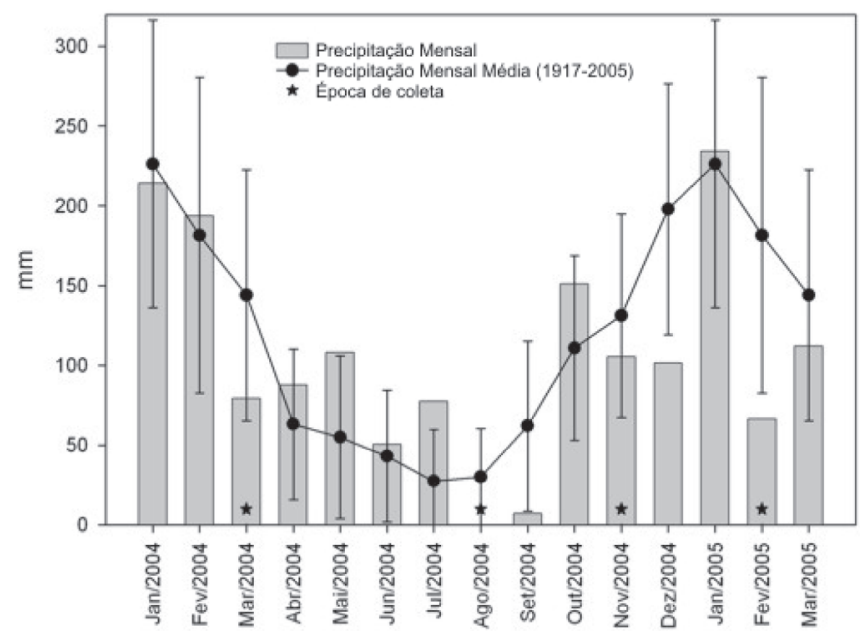

Figura 3. Precipitação mensal e precipitação mensal média (série histórica 1917-2005) para o período de estudo, segundo a Estação Meteorológica da Escola Superior de Agricultura Luiz de Queiroz, Universidade de São Paulo, Piracicaba-SP

Os processos convencionais de tratamento de água não são suficientes para remover eficientemente resíduos de agrotóxicos, de forma à atingir o padrão de potabilidade europeu e evitar os riscos a saúde humana, sendo necessária a adoção de técnicas mais eficientes, como adsorção em carvão ativado granulado após filtração em areia, osmose reversa ou nanofiltração, o que reverte em acréscimo no custo de tratamento ${ }^{39}$. Os níveis detectados nas amostras de água seriam certamente reduzidos pelos procedimentos adotados pelo Serviço Municipal de Água e Esgoto de Piracicaba (SEMAE), devido à inclusão de carvão ativado para garantir o padrão da Portaria brasileira. Krýsová et al. ${ }^{40}$ apontaram uma redução eficiente dos níveis de atrazina em água bruta de rio (3-4 $\mathrm{mg} \mathrm{L}^{-1}$ ) para 0,5-0,2 $\mathrm{mg} \mathrm{L}^{-1}$ pela filtração em carvão ativado, após as etapas de coagulação e filtração, as quais não alteraram as concentrações originais. Uma redução mais eficiente foi obtida pela substituição do carvão ativado por um processo de degradação fotocalítica com $\mathrm{TiO}_{2}$, atingindo níveis de $0,05 \mathrm{mg} \mathrm{L}^{-1}$. Pesquisas com fibra de carbono ativado têm demonstrado eficiência ainda maior de purificação da água ${ }^{41}$.

No entanto, no que se refere à proteção da vida aquática, pouca informação está disponível para dar suporte à tomada de decisão através de valores padrões de qualidade. É notório que para alguns agrotóxicos, peixes e moluscos são mais sensíveis que mamíferos e pássaros, devido a diferenças de sensibilidade do receptor ou órgão alvo ou a fatores toxicocinéticos, como absorção mais rápida e destoxificação mais lenta, resultando em concentrações mais elevadas $^{42}$. Para os herbicidas detectados não se observa qualquer padrão para garantir proteção da vida aquática em órgãos internacionais, como EPA e Environment Canada, que apresentam diretrizes para avaliação do risco ecológico, ainda não implementado no Brasil pela escassez de informações ecotoxicológicas para os organismos dos ecossistemas brasileiros. A legislação brasileira, através da Resolução CONAMA $357 / 05^{20}$ que define os padrões de qualidade de águas superficiais destinadas ao consumo humano e à proteção a vida aquática define níveis máximos apenas para os herbicidas atrazina, simazina e glifosato, detectados nas águas do Rio Corumbataí. Apenas atrazina apresentou valores superiores ao padrão definido nesta Resolução, igual ao da Portaria 518/04 do MS, valendo-se das ressalvas discutidas anteriormente para ametrina.

Dentre as moléculas detectadas, as triazinas apresentam 
toxicidade a humanos variando de atóxicas (simazina) a moderadamente tóxicas (atrazina), de acordo com os dados toxicológicos internacionais ${ }^{43}$. Porém, atrazina é conhecida por apresentar reduzida toxicidade para peixes e outros organismos aquáticos, com baixo nível de bioacumulação, e simazina é considerada levemente a praticamente atóxica para espécies aquáticas. Já a ametrina é caracterizada como moderadamente tóxica para peixes, altamente tóxica para crustáceos e moderadamente a altamente tóxica para moluscos. O herbicida glifosato, considerado atóxico para humanos e peixes, apresenta uma leve toxicidade para invertebrados aquáticos. Hexazinona é levemente tóxica para humanos por ingestão oral, peixes e outros organismos aquáticos. Clomazona apresenta leve toxicidade a humanos, vindo a afetar o fígado, toxicidade moderada para peixes e outros organismos aquáticos, com pequeno potencial de acúmulo ${ }^{43}$.

Para os pontos Coru01 e Coru02, cujas amostras foram submetidas também a testes ecotoxicológicos com diversos bioindicadores, como parte de outro projeto conduzido em concomitância à análise de resíduos de herbicidas, nenhum efeito adverso foi apontado pelos indicadores empregados, apesar dos níveis de herbicidas encontrados ${ }^{44}$.

De modo geral, os maiores níveis de herbicidas em água são encontrados no Rio Corumbataí, principalmente na região de Analândia, onde se vislumbra expansão e diversificação da atividade agrícola, com forte risco de erosão e comprometimento do lençol freático, uma vez que é área de afloramento e recarga do aquíffero Guarani ${ }^{22}$. De acordo com o Relatório Síntese da situação dos recursos hídricos das bacias hidrográficas dos Rios Piracicaba, Capivari e Jundiaî ${ }^{22}$, apenas os municípios de Piracicaba e Rio Claro captam água do Rio Corumbataí para o abastecimento público, a montante do ponto Coru06 e no ponto Coru03, respectivamente, estando menos sujeitos à presença de resíduos de herbicidas que as demais localidades.

Dentre os afluentes avaliados, o Rio Passa Cinco, considerado um dos mais limpos pelos parâmetros convencionais de qualidade, é o que apresenta, quando detectado, os menores níveis de agrotóxicos, com exceção de ametrina, verificada em níveis levemente superiores ao Ribeirão Claro, e hexazinona, não detectada neste último.

A persistência e particionamento destas moléculas no meio aquático são amplamente dependentes da temperatura, do $\mathrm{pH}$, do potencial redox e da quantidade de colóides e de íons (condutividade elétrica) no meio aquoso. Estes parâmetros também refletem as condições a que os organismos aquáticos estão expostos e são determinantes para sua atividade fisiológica e comportamental. A Tabela 2 apresenta os resultados dos parâmetros monitorados in situ no momento das coletas. A faixa de $\mathrm{pH}$ observada $(6,6-7,4)$ é considerada normal, em concordância com o padrão de qualidade da Resolução CONAMA 357/05, não sendo evidenciado um padrão espacial de ocorrência. As temperaturas observadas $\left(17,6-26,1^{\circ} \mathrm{C}\right)$ não refletem qualquer atividade antrópica ocorrendo nas águas, verificando-se apenas uma elevação de seus níveis à medida que se encaminha para a foz, em função da elevação da temperatura do ar ao longo da coleta.

Uma variação maior foi observada para a presença de íons dissolvidos (condutividade elétrica entre 18,8 e $330,0 \mu \mathrm{S} \mathrm{cm}^{-1}$ ), havendo uma elevação normal dos níveis no Rio Corumbataí a partir das áreas de nascente até sua foz. No entanto, valores mais elevados são observados após a confluência do Rio Corumbataí com o Ribeirão Claro (Coru05), seguido de uma redução ou manutenção destes níveis até a foz no Rio Piracicaba. Dentre os afluentes, o Rio Passa Cinco apresenta os menores valores, uma vez que sua bacia de captação envolve principalmente áreas agrícolas.

Um aspecto mais preocupante refere-se aos níveis de oxigênio dissolvido detectados na faixa de 2,53-9,5 $\mathrm{mg} \mathrm{L}^{-1}$, alguns inferiores aos limites estipulados pela Resolução CONAMA 357/05 para clas-
Tabela 2. Parâmetros físico-químicos da água do Rio Corumbataí e alguns afluentes

\begin{tabular}{|c|c|c|c|c|}
\hline $\begin{array}{l}\text { Ponto de } \\
\text { Amostragem }\end{array}$ & $\begin{array}{c}\text { Temperatura } \\
\left({ }^{\circ} \mathrm{C}\right)\end{array}$ & $\begin{array}{c}\text { Oxigênio } \\
\text { Dissolvido } \\
\left(\mathrm{mg} \mathrm{L}^{-1}\right)\end{array}$ & $\mathrm{pH}$ & $\begin{array}{c}\text { Condutividade } \\
\text { Elétrica } \\
\left(\mu \mathrm{S} \mathrm{cm}^{-1}\right)\end{array}$ \\
\hline & \multicolumn{4}{|c|}{ Coleta: 9/3/2004 } \\
\hline Coru01 & 21,7 & 7,80 & 7,00 & 29,3 \\
\hline Coru02 & 25,0 & 7,30 & 6,90 & 46,2 \\
\hline Coru03 & 23,7 & 6,90 & 7,00 & 63,1 \\
\hline Coru04 & 24,6 & 5,60 & 6,90 & 96,0 \\
\hline RibCla & 24,8 & 7,00 & 7,10 & 88,9 \\
\hline Coru05 & 25,5 & 7,20 & 7,40 & 118,2 \\
\hline PasCin & 25,3 & 7,50 & 7,30 & 71,1 \\
\hline \multirow[t]{2}{*}{ Coru06 } & 25,4 & 7,10 & 7,20 & 110,2 \\
\hline & \multicolumn{4}{|c|}{ Coleta: 23/8/2004 } \\
\hline Coru01 & 17,6 & 9,25 & 6,66 & 18,8 \\
\hline Coru02 & 19,0 & 9,18 & 6,90 & 29,6 \\
\hline Coru03 & 20,6 & 7,54 & 7,00 & 36,4 \\
\hline Coru04 & 21,8 & 3,11 & 6,70 & 113,0 \\
\hline RibCla & 21,7 & 5,08 & 6,60 & 119,4 \\
\hline Coru05 & 22,2 & 3,96 & 6,85 & 145,9 \\
\hline PasCin & 22,3 & 9,36 & 7,20 & 54,1 \\
\hline \multirow[t]{2}{*}{ Coru06 } & 23,0 & 8,25 & 7,13 & 154,9 \\
\hline & \multicolumn{4}{|c|}{ Coleta: 18/11/2004 } \\
\hline Coru01 & 21,4 & 9,50 & 6,86 & 21,1 \\
\hline Coru02 & 24,2 & 5,19 & 7,00 & 35,1 \\
\hline Coru03 & 23,9 & 5,47 & 7,02 & 39,5 \\
\hline Coru04 & 24,4 & 2,53 & 6,84 & 105,0 \\
\hline RibCla & 24,7 & 6,80 & 7,09 & 99,3 \\
\hline Coru05 & 25,1 & 4,80 & 7,03 & 136,9 \\
\hline PasCin & 25,3 & 4,52 & 7,27 & 58,0 \\
\hline \multirow[t]{2}{*}{ Coru06 } & 24,9 & 4,06 & 7,00 & 118,1 \\
\hline & \multicolumn{4}{|c|}{ Coleta: 14/2/2005 } \\
\hline Coru01 & 20,9 & 8,36 & 6,87 & 33,5 \\
\hline Coru02 & 22,0 & 8,20 & 6,96 & 35,0 \\
\hline Coru03 & 23,7 & 7,26 & 6,92 & 49,3 \\
\hline Coru04 & - & - & - & - \\
\hline RibCla & 24,9 & 6,93 & 7,03 & 93,4 \\
\hline Coru05 & 24,5 & 7,10 & 7,05 & 330,0 \\
\hline PasCin & - & - & - & - \\
\hline Coru06 & 26,1 & 7,01 & 7,28 & 148,0 \\
\hline
\end{tabular}

“_" dado não mensurado

sificação dos corpos d'água, refletindo a dificuldade de manter a vida aquática e de autodepuração deste sistema, além da oxidação de contaminantes passíveis de serem degradados por vias oxidativas. Os piores níveis foram observados no período de seca e no começo das chuvas. Segundo esta Resolução, os valores observados nos pontos Coru04 (3,11 $\left.\mathrm{mg} \mathrm{L}^{-1}\right)$ e Coru05 (3,96 $\left.\mathrm{mg} \mathrm{L}^{-1}\right)$, ambos a jusante do município de Rio Claro, levariam a incluí-los na Classe 4 (mínimo de 2,0 $\mathrm{mg} \mathrm{L}^{-1}$ ), com águas destinadas exclusivamente para navegação e harmonia paisagística, no período de seca. No início das chuvas, o ponto Coru04 ainda receberia o mesmo enquadramento e os pontos Coru05, Coru06 e PasCin seriam incluídos na Classe 3 (mínimo de $4,0 \mathrm{mg} \mathrm{L}^{-1}$ ), sem garantia de proteção à comunidade aquática, servindo ao consumo humano mediante tratamento convencional ou avançado. Os níveis observados no ponto Coru04 estão associados à presença de material orgânico oriundo do município de Rio 
Claro e ao represamento de águas neste ponto, fato não mais vislumbrado em virtude de rompimento desta barreira.

$\mathrm{Na}$ faixa de $\mathrm{pH}$ observada, as triazinas (ametrina: pka 4,1; atrazina: 1,68; simazina: 1,62 ) e a hexazinona (pka 2,2) encontramse na forma não-ionizada, com maior tendência de associação com os grupos hidrofóbicos do material orgânico, o qual, encontrando-se predominantemente na forma dissolvida, poderá favorecer a fotodegradação. Antunes ${ }^{29}$, avaliando metais pesados em sedimentos e sólidos em suspensão, paralelamente a este trabalho, encontrou níveis de carbono nos sólidos em suspensão, extraídos de amostras de água do ponto Coru05 do Rio Corumbataí, variando de 3,8 a 4,76\%, correspondendo a 1,01-1,55 mg L $\mathrm{m}^{-1}$. Determinações efetuadas pela Companhia de Tecnologia de Saneamento Ambiental, CETESB, apontam níveis de carbono orgânico dissolvido, COD, variando de

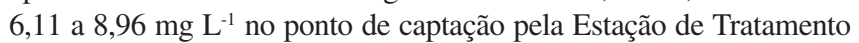
de Água de Piracicaba, no terço final do Rio Corumbataí ${ }^{45}$. Provavelmente, grande parte dos herbicidas encontram-se adsorvidos a estas partículas suspensas na coluna d'água. Entretanto, a adsorção pode apresentar um efeito protetor à ação da luz ${ }^{46}$. A presença de íons como nitrato e nitrito, detectados em níveis médios de 2,39 e 0,27 mg L ${ }^{1}$, respectivamente, no período de 1995-1997 nas águas do Corumbata $^{47}$, pode favorecer a oxidação destas triazinas pela formação de radicais hidroxila através da radiação solar.

Glifosato apresenta-se com carga iônica negativa (pka 5,6) nesta faixa de $\mathrm{pH}$, provavelmente associado aos sólidos em suspensão ou complexado a íons dissolvidos, principalmente metálicos, cuja presença é maior à medida que seguimos em direção a porção sul do Rio Corumbataí, indicado pela condutividade elétrica e pelos níveis de metais detectados, principalmente em sólidos em suspensão, por Antunes ${ }^{29}$. Não há informações científicas sobre o comportamento de clomazona em ambiente aquático. Sabe-se que o mesmo tende a formar ligações hidrofóbicas com matéria orgânica, reduzindo sua disponibilidade. Não há relatos de influência do conteúdo de oxigênio dissolvido e temperatura sobre o comportamento destas moléculas, nas faixas observadas. É notório que estes parâmetros são condicionantes da atividade metabólica de microrganismos, responsáveis pela principal via de degradação de muitos herbicidas, como os aqui detectados, podendo definir a persistência destas moléculas, principalmente nos trechos onde há menor fluxo de água no rio.

Tais evidências vêm a corroborar para a meta imposta ao Plano de Bacias da bacia hidrográfica dos Rios Piracicaba, Capivari e Jundiaí, de promover melhor zoneamento do uso e cobertura do solo em função da sua aptidão, preservando áreas de nascente e reduzindo a vulnerabilidade das zonas de recarga dos aqüíferos. No entanto, a ampliação deste estudo para um programa preliminar de monitoramento de longo prazo ainda faz-se necessária para melhor definição da vulnerabilidade espaço-temporal da sub-bacia do Rio Corumbataí, frente à variabilidade de condições edafoclimáticas e comportamentos de moléculas a elas associadas. Tal abordagem tem sido adotada em diversos países europeus antes de proporem modificações aos programas de monitoramento vigentes, como freqüência de monitoramento e poluentes sob avaliação ${ }^{48}$.

\section{CONCLUSÕES}

As triazinas (ametrina, atrazina e simazina), hexazinona, glifosato e clomazona foram os herbicidas observados em amostras de água da bacia do Rio Corumbataí. A composição arenosa do sedimento não propicia o acúmulo de herbicidas na forma adsorvida. As triazinas foram os herbicidas detectados em níveis mais elevados, acima do padrão de potabilidade brasileira, principalmente na região norte, onde se verificam áreas de recarga do aqüífero Guarani, de maior vulnerabilidade. A presença concomitante de moléculas em vários pontos da bacia atingiu uma carga residual de 2 até 13 vezes maior que o limite máximo de $0,5 \mu \mathrm{g} \mathrm{L}^{-1}$ para a soma de agrotóxicos, conforme estipulado para a Comunidade Européia. Não existem padrões internacionais para os herbicidas detectados e nos níveis presentes, de modo a evitar comprometimento à vida aquática, mas níveis de atrazina foram observados acima do padrão CONAMA 357/05, podendo haver risco ainda maior pela presença de ametrina, de maior toxicidade a crustáceos e moluscos, mas não incluída na lista de substâncias a serem monitoradas.

\section{MATERIAL SUPLEMENTAR}

Os resultados analíticos de resíduos de herbicidas em amostras de água e sedimento da sub-bacia do Rio Corumbataí encontramse disponíveis gratuitamente em http://quimicanova.sbq.org.br, na forma de arquivo PDF.

\section{AGRADECIMENTOS}

À Dr ${ }^{a}$. D. S. da Silva pela valiosa colaboração na correção deste artigo; à Fundação de Amparo a Pesquisa do Estado de São Paulo (FAPESP), pelo financiamento desta pesquisa e aos técnicos D. R. C. de Souza, M. M. Tavares e G. T. Ferreira, pelo apoio direto na análise de resíduos.

\section{REFERÊNCIAS}

1. Ritter, W. F.; J. Environ. Sci. Health, Part B 1990, 25, 1.

2. Sindicato Nacional da Indústria de Produtos para Defesa Agrícola (SINDAG); comunicação pessoal.

3. Comitê das bacias dos Rios Piracicaba, Capivari e Jundiaí: implantação, resultados e perspectivas, Arte Brasil: Campinas, 1996.

4. Brasil. Ministério do Meio Ambiente; Lei n.9.433, de 8 de janeiro de 1997. Institui a Política Nacional de Recursos Hídricos, cria o Sistema Nacional de Gerenciamento de Recursos Hídricos, regulamenta o inciso XIX do art. 21 da Constituição Federal e altera o art. $1^{\circ}$ da Lei n ${ }^{\circ} 8.001$, de 13 de março de 1990, que modificou a Lei ${ }^{\circ} 7.990$, de 28 de dezembro de 1989.

5. Sparovek, G.; Anisimova, M. A.; Kolb, M.; Bahadir, M.; Wehage, H.; Schnug, E.; J. Environ. Qual. 2001, 30, 2006.

6. Rissato, S. R.; Libânio, M.; Giafferis, G. P.; Gerenutti, M.; Quim. Nova 2004, 27, 739 .

7. Corbi, J. J.; Strixino, S. T.; Santos, A.; Del Grande, M.; Quim. Nova 2006, $29,61$.

8. Gomes, M. A. F.; Spadotto, C. A.; Lanchotte, V. L.; Pesticidas: $R$. Ecotoxicol. e Meio Ambiente 2001, 11, 65.

9. Gomes, M. A. F.; Spadotto, C. A. Em Biodegradação; Melo, I. S.; Azevedo, J. L., eds.; Embrapa Meio Ambiente: Jaguariúna, 2001.

10. Filizola, H. F.; Ferracini, V. L.; Sans, L. M. A.; Gomes, M. A. F.; Ferreira, C. J. A.; Pesq. Agropec. Bras. 2002, 37, 659.

11. Laabs, V.; Amelung, W.; Pinto, A. A.; Wantzen, M.; Silva, C. J.; Zech, W.; J. Environ. Qual. 2002, 31, 1636.

12. Silva, M. D.; Peralba, M. C. R.; Mattos, M. L. T.; Pesticidas: R. Ecotoxicol. e Meio Ambiente 2003, 13, 19.

13. Primel, E. G.; Zanella, R.; Kurz, M. H. S.; Gonçalves, F. F.; Machado, S. O.; Marchezan, E.; Quim. Nova 2005, 28, 605.

14. Rodrigues, G. S.; Paraíba, L. C.; Buschinelli, C. C.; Pesticidas: R. Ecotoxicol. e Meio Ambiente 1997, 7, 89.

15. Pessoa, M. C. P. Y.; Gomes, M. A. F.; Neves, M. C.; Cerdeira, A. L.; Souza, M. D.; Pesticidas: R. Ecotoxicol. e Meio Ambiente 2003, 13, 111.

16. Silva, D. M. L.; Dissertação de Mestrado, Universidade de São Paulo, Brasil, 2000.

17. Del Grande, M.; Rezende, M. O. O.; Rocha, O.; Quim. Nova 2003, 26, 678.

18. Salati, E.; Tese de Doutorado, Universidade de São Paulo, Brasil, 1996.

19. Palma-Silva, G. M.; Dissertação de Mestrado, Universidade Estadual Paulista, Brasil, 1999.

20. Brasil. Ministério do Meio Ambiente. Conselho Nacional do Meio Ambiente - CONAMA; Resolução n.357, de 17 de março de 2005. Dispõe sobre a classificação dos corpos de água e diretrizes ambientais para o seu enquadramento, bem como estabelece as condições e padrões de lançamento de efluentes, e dá outras providências. 
21. Jardim, G. M.; Dissertação de Mestrado, Universidade de São Paulo, Brasil, 2004.

22. Irrigart; Bacias hidrográficas dos Rios Piracicaba, Capivari e Jundiaí: situação dos recursos hídricos 2002/2003, FEHIDRO/PCJ/CBH-PCJ: Piracicaba, 2005.

23. Brasil. Ministério da Saúde; Portaria n.518, de 25 de março de 2004. Estabelece os procedimentos e responsabilidades relativos ao controle e vigilância da qualidade da água para consumo humano e seu padrão de potabilidade, e dá outras providências.

24. Armas, E. D.; Monteiro, R. T. R.; Amâncio, A. V.; Correa, R. M. L.; Guercio, M. A.; Quim. Nova 2005, 28, 975.

25. Dulka, J. J.; Anais do Workshop sobre Biodegradação, Campinas, Brasil, 1996.

26. Pimentel, D.; Acquay, H.; Biltonen, M.; Rice, P.; Silva, M.; Nelson, J.; Lipner, V.; Giordano, S.; Horowitz, A.; D'amore, M.; BioScience 1992, 42 750 .

27. Comitê Coordenador do Plano Estadual de Recursos Hídricos; Relatório de situação dos recursos hídricos do Estado de São Paulo, São Paulo, 1999.

28. Instituto de Pesquisas e Estudos Florestais; Plano Diretor: Conservação dos recursos hídricos por meio da recuperação e da conservação da cobertura florestal da bacia do Rio Corumbataí, Piracicaba, 2001.

29. Antunes, P. M.; Dissertação de Mestrado, Universidade de São Paulo, Brasil, 2006.

30. Araújo, A. S. F.; Monteiro, R. T. R.; Abakerli, R. B.; Chemosphere 2003 , $52,799$.

31. Souza, D. C.; Abakerli, R. B.; Fay, E. F.; Monteiro, R. T. R.; Resumos do $3^{\circ}$ Congresso Virtual Iberoamericano sobre Gestion de Calidad en Laboratorios, Valladolid, Espanha, 2005.
32. http://www4.anvisa.gov.br/agrosia/asp/default.asp, acessada em Março 2004.

33. Procópio, S. O.; Silva, A. A.; Vargas, L.; Ferreira, F. A.; Manejo de plantas daninhas na cultura da cana-de-açúcar, UFV: Viçosa, 2003.

34. Gerecke, A. C.; Schärer, M.; Singer, H. P.; Müller, S. R.; Schwarzenbach, R. P.; Sägesser, M.; Ochsenbein, U.; Popow, G.; Chemosphere 2002, 48, 307.

35. Leterme, B.; Vanclooster, M.; Rounsevell, M. D. A.; Bogaert, P.; Sci. Total Environ. 2006, 362, 124.

36. Kolpin, D. W.; Thurman, E. M.; Lee, E. A.; Meyer, M. T.; Furlong, E. T.; Glassmeyer, S. T.; Sci. Total Environ. 2006, 354, 191.

37. Gfrerer, M.; Wenzl, T.; Quan, X.; Platzer, B.; Lankmayr, E.; J. Biochem. Biophys. Methods 2002, 53, 217.

38. Beitz, H.; Schmidt, H.; Herzel, F. Em Pesticides in ground and surface water; Börner, H., ed.; Springer-Verlag: Berlin, 1994

39. Guyot, C. Em ref. 38.

40. Krýsová, H.; Krýsa, J.; Hubácková, J.; Tríska, J.; Jirkovský, J.; Chem. Listy 2005, 99, 179.

41. Martín-Gullón, I.; Font, R.; Water Res. 2001, 35, 516.

42. James, M. O. Em ref. 38

43. http://extoxnet.orst.edu, acessada em Abril 2006

44. Santos, M. A. P. F.; comunicação pessoal.

45. http://hydro.cria.org.br, acessada em Abril 2006.

46. Navarro, S.; Vela, N.; Giménez, M. J.; Navarro, G.; Sci. Total Environ. 2004, $329,87$.

47. http://www.cena.usp.br/piracena, acessada em Fevereiro 2003.

48. Liska, I.; Barceló, D.; Grasserbauer, M.; Trends Anal. Chem. 1996, 15, 326. 
DIAGNÓSTICO ESPAÇO-TEMPORAL DA OCORRÊNCIA DE HERBICIDAS NAS ÁGUAS SUPERFICIAIS E SEDIMENTOS DO RIO CORUMBATAÍ E PRINCIPAIS AFLUENTES

Eduardo Dutra de Armas", Regina Teresa Rosim Monteiro, Paula Munhoz Antunes, Maria Alice Penna Firme dos Santos e Plinio Barbosa de Camargo

Centro de Energia Nuclear na Agricultura, Universidade de São Paulo, CP 96, 13400-970 Piracicaba - SP, Brasil

Rosangela Blotta Abakerli

Embrapa Meio Ambiente, CP 69, 13820-000 Jaguariúna - SP, Brasil

Tabela 1S. Resultados analíticos de resíduos de herbicidas em amostras de água da sub-bacia do Rio Corumbataí

\begin{tabular}{|c|c|c|c|c|c|c|c|c|c|c|c|c|c|c|}
\hline \multirow{2}{*}{$\begin{array}{l}\text { Ponto de } \\
\text { amostragem }\end{array}$} & \multicolumn{14}{|c|}{ Concentração do herbicida $\left(\mu \mathrm{g} \mathrm{L}^{-1}\right)$} \\
\hline & Tebut & Hexaz & Sulf & Diur & Glif & Trif & Simaz & Atraz & Cloma & Aceto & Amet & Isox & Pendi & Total \\
\hline & \multicolumn{14}{|c|}{ Coleta: 09/03/2004 } \\
\hline 1 - Coru01 & ND & ND & ND & ND & ND & ND & ND & ND & ND & ND & ND & ND & ND & - \\
\hline 2 - Coru02 & ND & ND & ND & ND & $<$ LOQ & ND & ND & ND & ND & ND & ND & ND & ND & - \\
\hline 3 - Coru03 & ND & ND & ND & ND & $<$ LOQ & ND & ND & ND & ND & ND & ND & ND & ND & - \\
\hline 4 - Coru04 & ND & ND & ND & ND & $<$ LOQ & ND & ND & ND & ND & ND & ND & ND & ND & - \\
\hline 5 - RibCla & ND & ND & ND & ND & ND & ND & ND & ND & ND & ND & ND & ND & ND & - \\
\hline 6 - Coru05 & ND & ND & ND & ND & $<$ LOQ & ND & ND & ND & ND & ND & ND & ND & ND & - \\
\hline 7 - PasCin & ND & ND & ND & ND & ND & ND & ND & ND & ND & ND & ND & ND & ND & - \\
\hline \multirow[t]{2}{*}{8 - Coru06 } & ND & ND & ND & ND & ND & ND & ND & ND & ND & ND & ND & ND & ND & - \\
\hline & \multicolumn{14}{|c|}{ Coleta: 23/08/2004 } \\
\hline 1 - Coru01 & ND & ND & ND & ND & NA & ND & ND & ND & ND & ND & ND & ND & ND & - \\
\hline 2 - Coru02 & ND & ND & ND & ND & NA & ND & ND & ND & ND & ND & ND & ND & ND & - \\
\hline 3 - Coru03 & ND & 0,5 & ND & ND & NA & ND & ND & ND & ND & ND & ND & ND & ND & 0,5 \\
\hline 4 - Coru04 & ND & 0,3 & ND & ND & NA & ND & ND & ND & ND & ND & ND & ND & ND & 0,3 \\
\hline 5 - RibCla & ND & ND & ND & ND & NA & ND & ND & ND & ND & ND & ND & ND & ND & - \\
\hline 6 - Coru05 & ND & 0,4 & ND & ND & NA & ND & ND & ND & ND & ND & ND & ND & ND & 0,4 \\
\hline 7 - PasCin & ND & 0,3 & ND & ND & NA & ND & ND & ND & ND & ND & ND & ND & ND & 0,3 \\
\hline \multirow[t]{2}{*}{8 - Coru06 } & ND & 0,4 & ND & ND & NA & ND & ND & ND & ND & ND & ND & ND & ND & 0,4 \\
\hline & \multicolumn{14}{|c|}{ Coleta: 18/11/2004 } \\
\hline 1 - Coru01 & ND & ND & ND & ND & ND & ND & 0,6 & 2,7 & 0,4 & ND & 2,9 & ND & ND & 6,6 \\
\hline 2 - Coru02 & ND & ND & ND & ND & ND & ND & 0,5 & 2,2 & 0,4 & ND & 1,9 & ND & ND & 5,0 \\
\hline 3 - Coru03 & ND & ND & ND & ND & $<\mathrm{LOQ}$ & ND & ND & $<$ LOQ & ND & ND & $<\mathrm{LOQ}$ & ND & ND & - \\
\hline 4 - Coru04 & ND & ND & ND & ND & $<\mathrm{LOQ}$ & ND & $<$ LOQ & 1,2 & $<\mathrm{LOQ}$ & ND & 1,4 & ND & ND & 2,6 \\
\hline 5 - RibCla & ND & ND & ND & ND & $<\mathrm{LOQ}$ & ND & $<$ LOQ & 0,6 & $<\mathrm{LOQ}$ & ND & 0,7 & ND & ND & 1,3 \\
\hline 6 - Coru05 & ND & ND & ND & ND & $<\mathrm{LOQ}$ & ND & $\mathbf{0 , 3}$ & 1,6 & $<\mathrm{LOQ}$ & ND & 1,8 & ND & ND & 3,7 \\
\hline 7 - PasCin & ND & ND & ND & ND & $<\mathrm{LOQ}$ & ND & ND & $<$ LOQ & ND & ND & 1,0 & ND & ND & 1,0 \\
\hline \multirow[t]{2}{*}{8 - Coru06 } & ND & ND & ND & ND & $<\mathrm{LOQ}$ & ND & $<$ LOQ & $\mathbf{0 , 7}$ & $<\mathrm{LOQ}$ & ND & 0,8 & ND & ND & 1,5 \\
\hline & \multicolumn{14}{|c|}{ Coleta: 14/2/2005 } \\
\hline 1 - Coru01 & ND & ND & ND & ND & $<\mathrm{LOQ}$ & ND & ND & ND & ND & ND & NR & ND & ND & - \\
\hline 2 - Coru02 & ND & ND & ND & ND & ND & ND & ND & ND & ND & ND & NR & ND & ND & - \\
\hline 3 - Coru03 & ND & ND & ND & ND & ND & ND & ND & ND & ND & ND & NR & ND & ND & - \\
\hline 4 - Coru04 & $\mathrm{NC}$ & $\mathrm{NC}$ & $\mathrm{NC}$ & $\mathrm{NC}$ & $\mathrm{NC}$ & $\mathrm{NC}$ & $\mathrm{NC}$ & $\mathrm{NC}$ & $\mathrm{NC}$ & $\mathrm{NC}$ & $\mathrm{NC}$ & $\mathrm{NC}$ & $\mathrm{NC}$ & - \\
\hline 5 - RibCla & ND & ND & ND & ND & $<\mathrm{LOQ}$ & ND & ND & ND & ND & ND & NR & ND & ND & - \\
\hline 6 - Coru05 & ND & ND & ND & ND & $<\mathrm{LOQ}$ & ND & ND & ND & ND & ND & NR & ND & ND & - \\
\hline 7 - PasCin & $\mathrm{NC}$ & $\mathrm{NC}$ & $\mathrm{NC}$ & $\mathrm{NC}$ & $\mathrm{NC}$ & $\mathrm{NC}$ & $\mathrm{NC}$ & $\mathrm{NC}$ & $\mathrm{NC}$ & $\mathrm{NC}$ & $\mathrm{NC}$ & $\mathrm{NC}$ & $\mathrm{NC}$ & - \\
\hline 8 - Coru06 & ND & ND & ND & ND & ND & ND & ND & ND & ND & ND & NR & ND & ND & - \\
\hline LOQ & 0,2 & 0,2 & 0,2 & 0,2 & 1,0 & 0,3 & 0,3 & 0,3 & 0,3 & 0,3 & 0,3 & 0,3 & 0,3 & \\
\hline
\end{tabular}

Tebut - Tebutiurom; Hexaz - Hexazinona; Sulf - Sulfentrazona; Diur - Diurom; Glif - Glifosato; Trif - Trifluralina; Simaz Simazina; Atraz - Atrazina; Cloma - Clomazona; Aceto - Acetocloro; Amet - Ametrina; Isox - Isoxaflutol; Pendi - Pendimetalina NA - Não analisado; NC - Não coletado; ND - Não detectado; NR - Não recuperado; <LOQ - menor que o limite de quantificação 
Tabela 2S. Resultados analíticos de resíduos de herbicidas em amostras de sedimento da sub-bacia do Rio Corumbataí

\begin{tabular}{|c|c|c|c|c|c|c|c|c|c|c|c|c|c|c|}
\hline \multirow{2}{*}{$\begin{array}{l}\text { Ponto de } \\
\text { amostragem }\end{array}$} & \multicolumn{14}{|c|}{ Concentração do herbicida $\left(\mathrm{mg} \mathrm{kg}^{-1}\right)$} \\
\hline & Tebut & Hexaz & Sulf & Diur & Glif & Trif & Simaz & Atraz & Cloma & Aceto & Amet & Isox & Pendi & Total \\
\hline & \multicolumn{14}{|c|}{ Coleta: 9/3/2004 } \\
\hline 1 - Coru01 & NA & NA & NA & NA & $<\mathrm{LOQ}$ & ND & ND & ND & ND & ND & ND & ND & ND & - \\
\hline 2 - Coru02 & NA & NA & NA & NA & $<\mathrm{LOQ}$ & ND & ND & ND & ND & ND & ND & ND & ND & - \\
\hline 3 - Coru03 & NA & NA & NA & NA & $<\mathrm{LOQ}$ & ND & ND & ND & ND & ND & ND & ND & ND & - \\
\hline 4 - Coru04 & $\mathrm{NC}$ & $\mathrm{NC}$ & $\mathrm{NC}$ & $\mathrm{NC}$ & $\mathrm{NC}$ & $\mathrm{NC}$ & $\mathrm{NC}$ & $\mathrm{NC}$ & $\mathrm{NC}$ & $\mathrm{NC}$ & $\mathrm{NC}$ & $\mathrm{NC}$ & $\mathrm{NC}$ & - \\
\hline 5 - RibCla & $\mathrm{NC}$ & $\mathrm{NC}$ & $\mathrm{NC}$ & $\mathrm{NC}$ & $\mathrm{NC}$ & $\mathrm{NC}$ & $\mathrm{NC}$ & $\mathrm{NC}$ & $\mathrm{NC}$ & $\mathrm{NC}$ & $\mathrm{NC}$ & $\mathrm{NC}$ & $\mathrm{NC}$ & - \\
\hline 6 - Coru05 & NA & NA & NA & NA & $<$ LOQ & ND & ND & ND & ND & ND & ND & ND & ND & - \\
\hline 7 - PasCin & NA & NA & NA & NA & ND & ND & ND & ND & ND & ND & ND & ND & ND & - \\
\hline \multirow[t]{2}{*}{8 - Coru06 } & NA & NA & NA & NA & $<\mathrm{LOQ}$ & ND & ND & ND & ND & ND & ND & ND & ND & - \\
\hline & \multicolumn{14}{|c|}{ Coleta: 23/8/2004 } \\
\hline 1 - Coru01 & NA & NA & NA & NA & NA & ND & ND & ND & ND & ND & ND & ND & ND & - \\
\hline 2 - Coru02 & NA & NA & NA & NA & NA & ND & ND & ND & ND & ND & ND & ND & ND & - \\
\hline 3 - Coru03 & NA & NA & NA & NA & NA & ND & ND & ND & ND & ND & ND & ND & ND & - \\
\hline 4 - Coru04 & $\mathrm{NC}$ & $\mathrm{NC}$ & $\mathrm{NC}$ & $\mathrm{NC}$ & $\mathrm{NC}$ & $\mathrm{NC}$ & $\mathrm{NC}$ & $\mathrm{NC}$ & $\mathrm{NC}$ & $\mathrm{NC}$ & $\mathrm{NC}$ & $\mathrm{NC}$ & $\mathrm{NC}$ & - \\
\hline 5 - RibCla & $\mathrm{NC}$ & $\mathrm{NC}$ & $\mathrm{NC}$ & $\mathrm{NC}$ & $\mathrm{NC}$ & $\mathrm{NC}$ & $\mathrm{NC}$ & $\mathrm{NC}$ & $\mathrm{NC}$ & $\mathrm{NC}$ & $\mathrm{NC}$ & $\mathrm{NC}$ & $\mathrm{NC}$ & - \\
\hline 6 - Coru05 & NA & NA & NA & NA & NA & ND & ND & ND & ND & ND & ND & ND & ND & - \\
\hline 7 - PasCin & NA & NA & NA & NA & NA & ND & ND & ND & ND & ND & ND & ND & ND & - \\
\hline 8 - Coru06 & NA & NA & NA & NA & NA & ND & ND & ND & ND & ND & ND & ND & ND & - \\
\hline
\end{tabular}

\begin{tabular}{|c|c|c|c|c|c|c|c|c|c|c|c|c|c|c|}
\hline \multirow[b]{2}{*}{1 - Coru01 } & \multicolumn{14}{|c|}{ Coleta: 18/11/2004 } \\
\hline & NA & NA & NA & NA & $<\mathrm{LOQ}$ & ND & ND & ND & ND & ND & ND & ND & ND & - \\
\hline 2 - Coru02 & $\mathrm{NC}$ & $\mathrm{NC}$ & $\mathrm{NC}$ & $\mathrm{NC}$ & $\mathrm{NC}$ & $\mathrm{NC}$ & $\mathrm{NC}$ & $\mathrm{NC}$ & $\mathrm{NC}$ & $\mathrm{NC}$ & $\mathrm{NC}$ & $\mathrm{NC}$ & $\mathrm{NC}$ & - \\
\hline 3 - Coru03 & NA & NA & NA & NA & ND & ND & ND & ND & ND & ND & ND & ND & ND & - \\
\hline 4 - Coru04 & $\mathrm{NC}$ & $\mathrm{NC}$ & $\mathrm{NC}$ & $\mathrm{NC}$ & $\mathrm{NC}$ & $\mathrm{NC}$ & $\mathrm{NC}$ & $\mathrm{NC}$ & $\mathrm{NC}$ & $\mathrm{NC}$ & $\mathrm{NC}$ & $\mathrm{NC}$ & $\mathrm{NC}$ & - \\
\hline 5 - RibCla & $\mathrm{NC}$ & $\mathrm{NC}$ & $\mathrm{NC}$ & $\mathrm{NC}$ & $\mathrm{NC}$ & $\mathrm{NC}$ & $\mathrm{NC}$ & $\mathrm{NC}$ & $\mathrm{NC}$ & $\mathrm{NC}$ & $\mathrm{NC}$ & $\mathrm{NC}$ & $\mathrm{NC}$ & - \\
\hline 6 - Coru05 & NA & NA & NA & NA & $<$ LOQ & ND & ND & ND & ND & ND & ND & ND & ND & - \\
\hline 7 - PasCin & NA & NA & NA & NA & $<\mathrm{LOQ}$ & ND & ND & ND & ND & ND & ND & ND & ND & - \\
\hline \multirow[t]{2}{*}{8 - Coru06 } & NA & NA & NA & NA & $<\mathrm{LOQ}$ & ND & ND & ND & ND & ND & 0,01 & ND & ND & 0,01 \\
\hline & \multicolumn{14}{|c|}{ Coleta: 14/2/2005 } \\
\hline 1 - Coru01 & NA & NA & NA & NA & NA & ND & ND & ND & ND & ND & ND & ND & ND & - \\
\hline 2 - Coru02 & $\mathrm{NC}$ & $\mathrm{NC}$ & $\mathrm{NC}$ & $\mathrm{NC}$ & $\mathrm{NC}$ & $\mathrm{NC}$ & $\mathrm{NC}$ & $\mathrm{NC}$ & $\mathrm{NC}$ & $\mathrm{NC}$ & $\mathrm{NC}$ & $\mathrm{NC}$ & $\mathrm{NC}$ & - \\
\hline 3 - Coru03 & NA & NA & NA & NA & NA & ND & ND & ND & ND & ND & ND & ND & ND & - \\
\hline 4 - Coru04 & $\mathrm{NC}$ & $\mathrm{NC}$ & $\mathrm{NC}$ & $\mathrm{NC}$ & $\mathrm{NC}$ & $\mathrm{NC}$ & $\mathrm{NC}$ & $\mathrm{NC}$ & $\mathrm{NC}$ & $\mathrm{NC}$ & $\mathrm{NC}$ & $\mathrm{NC}$ & $\mathrm{NC}$ & - \\
\hline 5 - RibCla & $\mathrm{NC}$ & $\mathrm{NC}$ & $\mathrm{NC}$ & $\mathrm{NC}$ & $\mathrm{NC}$ & $\mathrm{NC}$ & $\mathrm{NC}$ & $\mathrm{NC}$ & $\mathrm{NC}$ & $\mathrm{NC}$ & $\mathrm{NC}$ & $\mathrm{NC}$ & $\mathrm{NC}$ & - \\
\hline 6 - Coru05 & NA & NA & NA & NA & NA & ND & ND & ND & ND & ND & ND & ND & ND & - \\
\hline 7 - PasCin & $\mathrm{NC}$ & $\mathrm{NC}$ & $\mathrm{NC}$ & $\mathrm{NC}$ & $\mathrm{NC}$ & $\mathrm{NC}$ & $\mathrm{NC}$ & $\mathrm{NC}$ & $\mathrm{NC}$ & $\mathrm{NC}$ & $\mathrm{NC}$ & $\mathrm{NC}$ & $\mathrm{NC}$ & - \\
\hline 8 - Coru06 & NA & NA & NA & NA & NA & ND & ND & ND & ND & ND & ND & ND & ND & - \\
\hline LOQ & & & & & 0,05 & 0,01 & 0,01 & 0,01 & 0,01 & 0,01 & 0,01 & 0,01 & 0,01 & \\
\hline
\end{tabular}

Tebut - Tebutiurom; Hexaz - Hexazinona; Sulf - Sulfentrazona; Diur - Diurom; Glif - Glifosato; Trif - Trifluralina; Simaz - Simazina; Atraz - Atrazina; Cloma - Clomazona; Aceto - Acetocloro; Amet - Ametrina; Isox - Isoxaflutol; Pendi - Pendimetalina

NA - Não analisado; NC - Não coletado; ND - Não detectado; NR - Não recuperado; <LOQ - menor que o limite de quantificação 